\title{
Floffy: Designing an Outdoor Robot for Children
}

\author{
Omar Mubin ${ }^{1}$, Luke Vink $^{2}$, Pieter Oosterwijk ${ }^{2}$, \\ Abdullah Al Mahmud ${ }^{3}$, and Suleman Shahid ${ }^{4}$ \\ ${ }^{1}$ University of Western Sydney, Australia \\ ${ }^{2}$ Eindhoven University of Technology, The Netherlands \\ ${ }^{3}$ Department of Industrial Design, Delft University of Technology, The Netherlands \\ ${ }^{4}$ Department of Communication and Information Sciences, \\ Tilburg University, The Netherlands \\ o.mubin@uws.edu.au, luke@lukevink.com, \\ p.j.m.oosterwijk@student.tue.nl, a.almahmud@tudelft.nl, \\ s.shahid@uvt.nl
}

\begin{abstract}
In our research we utilized the domain of entertainment robotics to educate children on the principles of environmental awareness by playful means outdoors. Our research revolved around the iterative design of Floffy: the environmental robot, which was essentially a playful toy robot that would respond positively to interaction that was beneficial for the environment and the child's own well being and negatively to interaction or behaviour that was detrimental to the surroundings. We conducted an explorative, informal evaluation of Floffy with two small groups of children and they rated their experience with it positively. Our results show that there is potential in utilizing entertainment robots to educate children on serious and critical issues such as saving our environment and being sustainable.
\end{abstract}

Keywords: Child-robot interaction, Arduino, Environment.

\section{Introduction}

In today's world dominated by industrial, mechanical and technological production, slowly sustainability and environmental awareness are gaining importance. Great emphasis has been laid forward on developing ventures that can educate people in protecting and preserving their environment. Educating our children on the importance of caring for the world we live in is also imperative, as awareness needs to start bottom up. The use of entertainment, games and robots to educate children is an exciting research area $[1,2]$. LEGO Mindstorms is a well renowned learning tool, combining the aspects of play, games, robots and education [3].

The number of robots in our society is increasing rapidly and already in 2008 the sales of service robots outnumbered the sales of industrial robots [4]. Incorporating robots in behavioural revolutions therefore seems like an obvious choice. Gradually, users' interactions with robotic systems in their daily life will increase therefore there is great potential in utilizing those interactions to educate the users about various issues related to the betterment of the world. The notion of propagating environmental 
awareness with the help of robots is generally an untapped domain. An upcoming research stream is that of persuasive technology, where robots have been used to persuade users to save energy [5]. However what is measured is the power of verbal persuasion by robotic agents but there is no physical interaction involved with the robot. In addition there is no effect of the act of saving energy on the robot itself. Therefore our focus was on creating a robot that could educate its users on environmental protection, such that the robot was at the source of the environmental consciousness behaviour. The use of technology in general to instil environmental awareness in people is not new [6].

We wished to focus on child robot interaction for our research on creating a robot that would be environmentally friendly. Children of today will be the adults of tomorrow therefore any gradual behavioural revolutions in our society should also target children and not only adults [7]. There has been extensive research on educating children on the importance of preserving their environment [8]. One relevant prior work within the domain of environmental education using robots is that of [9], where they developed an ecologically friendly robot. However their target group was university students and the results of their evaluation are fairly limited, as only a questionnaire was used. The choice of age of our target group was another key decision. From prior literature [10], we deduced that at the age of 12 years old and more, children start to become more in touch with reality and develop a sense of reasoning and logic. In addition their cognitive thought processes become less egocentric and they start to think about their surroundings and the people in them. All in all, we felt that children of this age group would be willing to appreciate the principle of environmental awareness much better than younger children. This is further substantiated by the fact that children of the age of around 12 years would have probably gone through some environmental awareness programs at school or their local community. The intention of our research was not to replace such avenues but rather supplement them and provide a playful yet educational toy like product to children.

To summarize the design statement of our research was, "To design and evaluate an animated toy robot that in an organic form, represents appropriate animated behaviour to show a child around the age of 12 years old the importance of our natural environment." We realized that we would be unable to adapt a robot off the shelf (primarily because there is no such robot available that can effectively propagate environmental awareness to young children in a playful way). Our aim was to therefore indigenously create such a robot. In the following sections of the paper we first describe the iterative design process of Floffy and then the evaluation study that we carried out with children.

\section{Design Process}

Given that we were targeting a specific user group and that we had certain interaction trends in mind we outlined the following design decisions. These decisions were primarily informed from prior literature on entertainment robotics [11] (design decisions 1 and 2) and also from the brainstorming sessions we conducted with the research team (design decisions 3 and 4). 
1. The robot should display certain animations (or behavior) to inform how it is feeling at a particular moment.

2. The robot should allow for personal, playful and tangible interaction.

3. The robot should physically represent a toy or a playful creature. However its representation need not be very literal, to allow for children to associate with easily, as children in the age group of 12 years old are likely to discover abstract signals and icons [10].

4. There must be elements of environmental consciousness built into the robot's interaction model. For e.g. aspects such as outdoors is better that indoors in a sustainable, environmental and general wellbeing sense (as evidenced in [12]), water is better than battery/water is renewable (as evidenced in [13]), etc. must relate back to the animations of the robot.

We followed an iterative process with the design of our robot. The first step of the design process was a series of several brainstorming sessions that we mentioned earlier. The following "physical attributes" of our robot were also brought forward as a result of our brainstorming sessions (along with the earlier mentioned design guidelines). The sessions were held within the research team (5 members) where one of the member took on the role of a facilitator and a second the role of the note taker. As part of the sessions we compared and contrasted existing entertainment products (toy robots) for children of our age group. Summarized below are the key attributes of our intended robot:

- The robot must move, i.e. leg/limb movement is an important design aspect to look into. A mobile robot would provide us with a richer array of interaction possibilities.

- The display of colors and lighting is also very important to utilize interaction possibilities.

- The robot should have an option to change shape.

The choice of prototyping platform was also a key design decision. We went ahead with the Arduino prototyping kit, which is a low-cost kit that comes with a microcontroller and various props that function as sensors and actuators. It is used fairly extensively in design research to create robotic prototypes [14]. We acknowledged that focusing on a solitary robot would not be an intelligent design decision. What was imperative was that we followed an iterative process, merging beneficial features from sub-prototypes. We now briefly present some of our intermediate designs (built using Arduino) (see Figure 1) that eventually led to the creation of Floffy.

Sub-prototype 1. The wagging tail. The Wagging Tail was an exploration of fluid movement to distinguish two opposing emotions (i.e. happy and sad) with two opposing movements, ultimately mimicking the shape dynamics of an animal tail.

Sub-prototype 2. The triangular robot. The triangular robot was again an expression of two opposing emotions. The triangle would be content in its default state (as seen in the figure). When suddenly approached by an unknown object in its proximity, the triangle would get scared and fall on its point.

Sub-prototype 3. Mr Googly. Mr Googly was an exploration of how the exterior of our robot could look like aesthetically and how it would feel in a material sense. 
We specially focused on its big eyes, inspired by characters in children's TV shows such as in Sesame Street. The inside of the eyes contained RGB LED's. The choice of what colors in the LED's would depict what emotions was inherited from [15].

Sub-prototype 4. Walter Cannon. The Walter Cannon robot combined emotion and mechanics successfully using a proximity sensor to alternate its position and stance. If a user would draw his/her hand towards the robot it would quickly retreat.

Sub-prototype 5. Raffelsia. In order to explore techniques to portray the environment, we created the Raffelsia (flower like) robot. It consisted of an in-house built water sensor and an ultraviolet light sensor. The "petals" of the robot would open and shut depending on water intake and if it was outdoors or not.
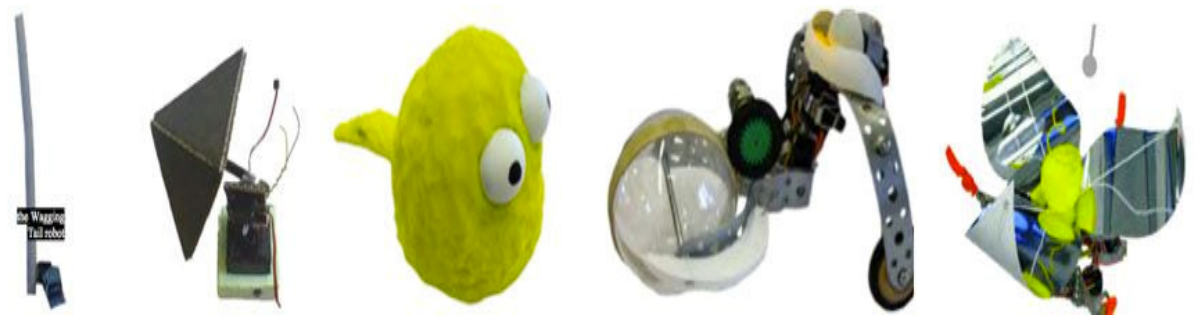

Fig. 1. Sub prototypes (from L-R): The wagging tail, the triangular robot, mr googly, walter cannon and raffelsia

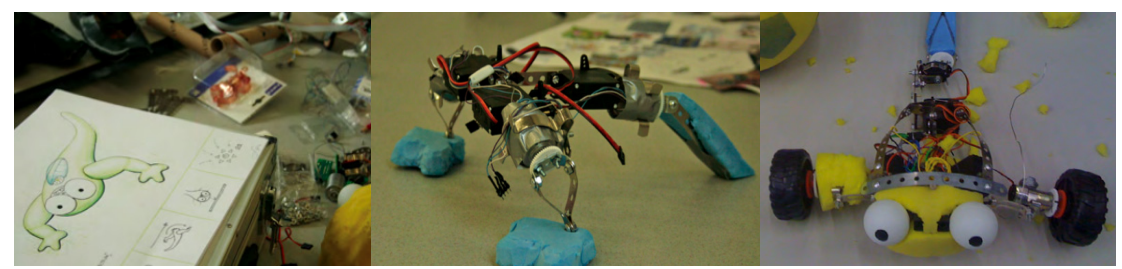

Fig. 2. Initial sketch of Floffy, the first structure of Floffy and redesign of Floffy (left to right)

\section{Development of the Robot}

Drawing on our experiences of creating the sub-prototypes we moved to the next stage of actually creating Floffy. We tried to incorporate facets of knowledge from the earlier design phase into our final design by utilizing the Questions, Options and Criteria Technique executed within the design team to decipher which features of the sub-prototypes would be the most critical for our final product. This led to for e.g. the water sensor mechanism of Raffelsia being retained for the final implementation. The first step was to sketch the prospective design of Floffy on paper (see Figure 2). We drew up several forms for the robot including 4, 5 and no legged creatures. Eventually, we decided on a robot with 3 limbs. This meant that whatever we worked out for the front two limbs, we could most likely make it move. The result was a gecko inspired creature.

The Personality of Floffy. Before creating the robot we agreed on an interaction scenario of Floffy based on its hypothetical personality: "Firstly, Floffy requires water 
to live. When Floffy is inside it responds with anger and sadness. It will jump and run away. When taken outdoors, its behavior changes and he begins to jump and play."

Building Floffy. Once we had an initial sketch and initial persona of Floffy in mind, the next step was to build the main frame/body of the robot, followed by adding sensors and finally the last stage of the building process was to focus on the physical attributes such as the outer skin and the padding to give it volume. We will now briefly describe each stage of the building process.

The frame of the robot was divided into modules, such as the two arms and the tail. While we built the individual modules we would predict the final shape of the robot with overlays to help in visualizing the outlook of the robot. Due to our success in the sub-prototype 5: Raffielsa, we wished to have arm movement in Floffy and we consequently arrived at the structure shown in Figure 3 (top). Due to a restriction on the number of ports on the Arduino board we used motors instead of servos.

We soon realized that due to a weight issue we could not achieve proper arm movements with the motors. They were unable to lift let alone move the robot. We also faced an issue with precise positioning of the continuous motor. Therefore our redesign involved the incorporation of wheels (see Figure 3 - bottom). The eyes of Floffy were adapted from sub-prototype 3: Mr Googly and the water sensor and solar panel from sub-prototype 5: Raffelsia. The movements of Floffy were based on our sub-prototype 4: Walter Cannon. The fur was also fairly complex to integrate because every part of the robot that moved had to be considered in conjunction with the placement of the water sensor and the solar panel.

The Behaviors of Floffy. Floffy, used a proximity sensor to determine in combination with a solar panel and water sensor, 9 different behavioral states. These were categorized into 3 groups determined by the current status of the robot. The 3 major states, 'near death', 'inside' and 'outside' were guided functionally but the existence of water (as food/energy) and then further broken down into 3 levels based on the proximity of the user. In the first major state; 'near death', Floffy would 'writher' in desperation (see Figure 5), if a user was in range (roughly $30 \mathrm{~cm}$ ). As the person drew closer, Floffy would show a heightened and excitable desire for water by jumping swiftly. The second state, where Floffy was fed but inside, the robot would show negative behaviors, as an inclination to go outdoors. The closer the user got, the more Floffy would retreat and move away. In the final state; 'Outside', Floffy would show greater interest the more closer a user was by drawing itself towards the user. All the while, the robots eyes were changed in attempt to display these behavioral states. For example in a state of anger, Floffy would flash his eyes red, while joy or happiness showed the flashing of green eyes and desperation with orange.

\section{Evaluation}

Method. In order to evaluate our design of Floffy, we conducted a series of exploratory qualitative evaluation sessions with a group of children using the think aloud methodology. The think aloud protocol has shown to be effective with children [16] as compared to other standard evaluation methods such as questionnaires. 


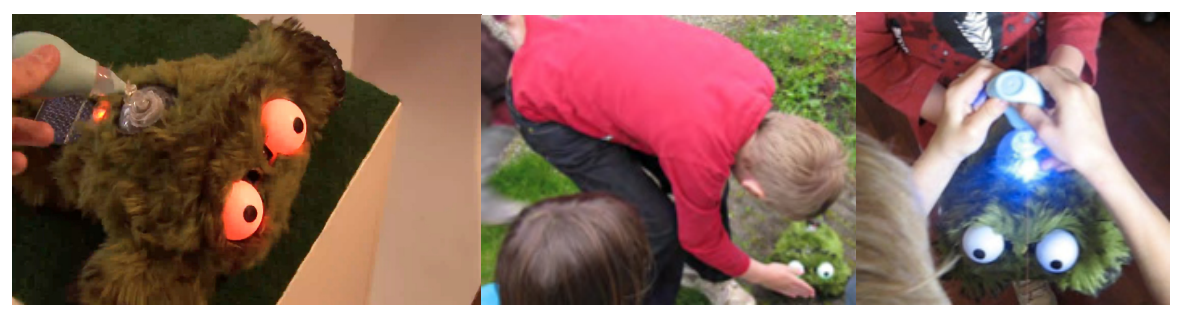

Fig. 3. Floffy showing desperation for water in the state of 'near death' (left most); Children interacting with Floffy

The evaluation was spread across two separate sessions, each involving 3 children (3M, 3F, average age: 12.2 years). Appropriate consent was gathered from their parents. The objective of the evaluation was to ascertain if the children could understand the rationale behind Floffy and interact and engage with it. The sessions started off by giving a small introduction of Floffy while indoors. The children were allowed free and open interactions (for 20 minutes) by bringing their hands close to Floffy (see Figure 6). They were also allowed to interact cooperatively with the robot and figure out how it all worked. At this juncture, the facilitators monitored what the feedback was from the children and also encouraged the children to elicit what they felt about each interaction step with the robot. The children were then given a water feeder without letting them know what they must do with it. The children would sooner or later discover that water would need to be dropped into Floffy (see Figure 6). As the facilitators we observed the reactions and thoughts of the children throughout the whole process. Floffy was then taken outside and the actions were repeated (free explorations for 20 minutes). We would like to share some interesting anecdotal notes from the evaluation.

Results. In the first session, one child attempted to pat Floffy from the front and due to Floffy's reaction with the proximity sensor, coupled with the robots lack of sunlight, it began to move fast and wildly (signifying an angry movement). The child became reluctant and took his hand away only to be later calmed by our explanation that Floffy is safe. In the second session, one of the girls exclaimed to us: "He (Floffy) likes it better outside!" When we questioned further as to why, the girls responded with, "Because his eyes are red inside and green outside". The children enjoyed playing with Floffy and 5 out of 6 children were able to correctly deduce what the purpose and intention of Floffy and its interactions was.

\section{$5 \quad$ Discussion and Future Work}

With our research we have investigated the impact robots can have on educating children in a fun and enjoyable way. We would like to summarize the key novel aspects of Floffy": 
- Floffy is unique. No other robot on the market is "fed water" or "desires the sun". This robot is designed to teach children to love the environment via its unique interaction mechanisms.

- Designed to be happier outside, children will prefer to play with Floffy outside at the same time learning to appreciate the environment the way Floffy does.

- Floffy convinces children into thinking it is powered by water, which is both inspiring for children and possible in the future. Floffy subtly suggests that the future of power is alternative energy.

One of the limitations of the work presented in the research so far is that to fully validate our claims we would need to carry out a large-scale evaluation with a substantial number of children. Therefore as part of our future work we would like to carry out extensive user evaluations with Floffy and children of 12 years old, which will help us in finalizing the granularity and specifications of the behavioral variations that we have implemented and also contemplate any redesign and structural modifications. We wish to conduct empirical evaluations of quantitative nature, enabling us to confirm the connection and link between the behavior of the Floffy and the interpretation of the child. We will also be able to establish what kind of actions and responses stimulate interaction between children and robots.

Acknowledgements. We thank the children and their parents for the cooperation.

\section{References}

1. Han, J., Jo, M., Park, S., Kim, S.: The educational use of home robots for children. In: ROMAN 2005, pp. 378-383. IEEE Press, New York (2005)

2. Fisch, S.M.: Making educational computer games educational. In: Interaction Design and Children (IDC 2005), pp. 56-61. ACM Press, New York (2005)

3. Mubin, O., Bartneck, C., Feijs, L., Hooft van Huysduynen, H., Hu, J., Muelver, J.: Improving Speech Recognition with the Robot Interaction Language. Disruptive Science and Technology 1(2), 79-88 (2012)

4. International Federation of Robotics.: World Robotics Survey (2008)

5. Midden, C., Ham, J.: Using negative and positive social feedback from a robotic agent to save energy. In: International Conference on Persuasive Technology, pp. 12-16. ACM Press (2009)

6. Morgil, I., Arda, S., Secken, N., Yavuz, S., Oskay, O.O.: The influence of computerassisted education on environmental knowledge and environmental awareness. Chemistry Education: Research and Practice 5(2), 99-110 (2004)

7. O'Brien, K., Stoner, D.K.: Increasing environmental awareness through children's literature. The Reading Teacher, 14-19 (1987)

8. Brynjegard, S.: School Gardens: Raising Environmental Awareness in Children. ERIC (2001)

9. Yamazaki, A., Masuda, R.: Development of an eco-communication robot for enhanced environmental education. In: International Symposium on System Integration, pp. 140-145. IEEE Press, New York (2010)

10. Markopoulos, P., Bekker, M.: Interaction design and children. Interacting with Computers 15(2), 141-149 (2003) 
11. Graf, B., Oliver, B.: Entertainment Robotics: Examples, Key Technologies and Perspectives. Safety 6(7) (2002)

12. Coon, J.T., Boddy, K., Stein, K., Whear, R., Barton, J., Depledge, M.H.: Does participating in physical activity in outdoor natural environments have a greater effect on physical and mental wellbeing than physical activity indoors? A systematic review. Environ. Sci. Technol. 45(5), 1761-1772 (2011)

13. Frey, G.W., Linke, D.M.: Hydropower as a renewable and sustainable energy resource meeting global energy challenges in a reasonable way. Energy Policy 30(14), 1261-1265 (2002)

14. Alers, S., Hu, J.: AdMoVeo: A robotic platform for teaching creative programming to designers. In: Chang, M., Kuo, R., Kinshuk, Chen, G.-D., Hirose, M. (eds.) Edutainment 2009. LNCS, vol. 5670, pp. 410-421. Springer, Heidelberg (2009)

15. Russell, J.A.: Circumplex models of personality and emotions. American Psychological Association (1997)

16. Donker, A., Markopoulos, P.: A comparison of think-aloud, questionnaires and interviews for testing usability with children. People and Computers 16, 305-316 (2002) 